\title{
EUXESTA STIGMATIAS LOEW, AN OTITID FLY INFESTING EAR CORN IN PUERTO RICO
}

By Bernard A. App, Bureau of Entomology and Plant Quarentine, U. S. Department of Agriculture.

This paper reports the results of observations made on the otitid fly Euxesta stigmatias Loew in connection with investigations on insects attacking corn in Puerto Rico under special funds provided to the Bureau of Entomology and Plant Quarantine of the U. S. Department of Agriculture. The studies were conducted in cooperation with the Experiment Station of the U. S. Department of Agricutulre at Mayagüez, P. R., where laboratory and other facilities were provided for the work. The Isabela Substation of the Agricultural Experiment Station of the University of Puerto Rico, Río Piedras, also cooperated in supplying plots for some of the experiments. Acknowledgement is also made of the advice and assistance rendered by various members of the Station staff. The observations were made from August 1935 to June 1936.

When these studies were begun, corn ears were found infested with dipterous maggois, which caused a very unsightly and malodorous condition, spoiling many ears for market as roasting ears. It was at first thought that the high humidity and heat prevailing in Puerto Rico had caused the silks to rot and that the maggots were feeding on this decaying material. The large number of ears to infested, however, seamed to indicate that these maggots were inflicting primary injury to corn. Further examination disclosed many whitish, elongate eggs deposited on fresh silks near the juncture with the husks. Some of these eggs, together with maggots from infested ears, were taken to the laboratory and reared to maturity on fresh corn silks, and were thus found to repesent the same species. Samples of both lots were sent to Washington, where they were determined as the otitid fly Euxesta stigmatias Loew (fig. 1).

\section{Distribution}

This fly seems to be generally distributed throughout the tropical part of the Western Hemisphere. Records of the U. S. National Museum show it to be reported from the following locations: 
West Indies: Puerto Rico, Cuba, Dominican Republic, Nassau, Virgin Islands.

British West Indies: Barbados, Dominica, St. Vincent, Jamaica.

Central America: Canal Zone, Panama.

South America: Brazil, Bolivia, Paraguay, Perú.

North America: Mexico, Florida.

According to these records the fly has been taken on sugareane, guava, corn, Eugenia spp., orange, and the stem of banana.

\section{AbUnd.ince}

No field of corn in the ear stage was examined in which this maggot was not present, and usually infesting a large majority of the ears. The percentage of infested ears seems dependent on the stage of maturity of the corn. The ears usually become infested when they are one to two weeks past silking, but as the corn matures the maggots leave the ears to pupate. Table I gives the percentage of infested ears in some fields examined throughout the period of observation. Field counts were made nearly every month and showed the fly to be present at all seasons.

TABLE 1-PERCENTAGE OF CORN EARS INFESTED WITH MAGGOTS OF EUXESTA STIGMATIAS IN DIFFERENT FIELDS EXAMINED IN PUERTO RICO

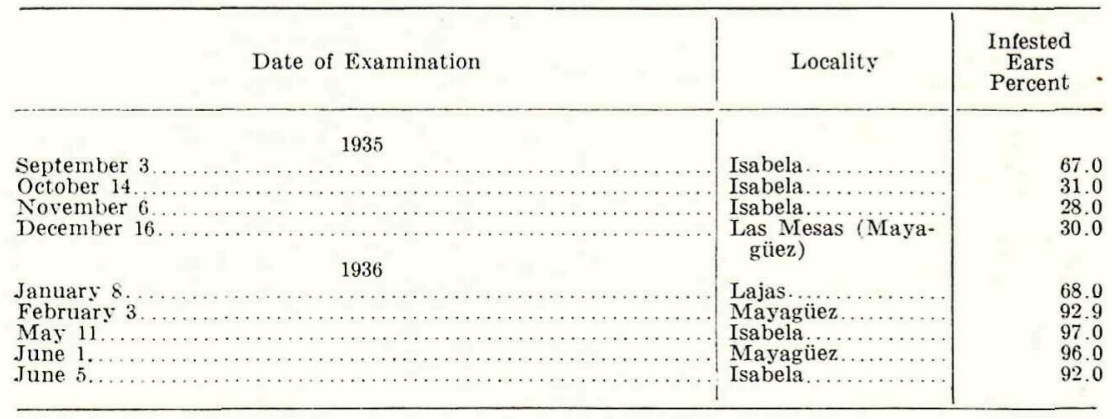

\section{DAMAGE}

There is little exterior evidence of the infestation, as the silks usually dry in the normal manner. Examination of an infested ear reveals that inside the husks, from the tip where the eggs hatched, the silks are rotted down to the grain. The kernels on the tip of the ear are only hollow shells, the maggot having consumed their entire contents. The maggots work between the rows of grain near the cob, they enter the kernal at the bottom, consuming its contents and learing a hollow shell, and then attack the next kernel. In most 
cases only a few kernels at the tip are destroyed, but many ears were infested with maggots in their entire length. Frequently maggots were working in the pith of the ear, which resulted in a stunted, soft ear bearing grain of little value, when any was produced. In field corn most of the maggots har pupated by the time it was ready to harvest. A mold seems to follow the feeding of these maggots, making it impossible to leave seed ears in the field until fully mature. Perhaps the greatest damage caused by this insect is the reduction of the market value of roasting ears by the unsightly and malodorous condition imparted to them.

\section{Life History and Description of Stages}

Eggs.-The minute, elongate, whitish eggs (fig. 2) are laid just below the tips of the husks, and usually in strings fastened end to end. During oviposition the female stands on the ear and curves her ovipositor down below the tip of the husk. Some eg'gs are laid as soon as the silks appear, and as the silks grow out the eggs are pushed out with them and remain attached to them. More often, however, the eggs are laid after the silks have grown out, and they remain just below the iip of the husk until they hatch. Of 200 plants examined during December 1935, 191 were observed to produce silk, and of this number 189, or 98.9 percent, were infested with eggs of this otitid. On this group of plants the silks became infested with egg's on an average of 1.12 days after they appeared. The number of egg's laid on one ear ranged from a few dozen to several hundred. Some of the eggs are lost as the silks grow out, but six ears brought into the laboratory were found to contain 558, 685, 47, 146, 431, and $248 \mathrm{eggs}$, respectively, or an average of $352.5 \mathrm{eggs}$ per ear. The length of the egg stage is from two to four days. In the fall of 1935 a sample of eggs began hatching on the second day after deposition and completed hatching by the fourth day. On June 18, 1936, some eggs laid the previous day were brought into the laboratory, where they began hatching on June 21 and completed hatching by June 22.

Larvae.-The larvae are also minute and white in color, with darker spiracles and mouth parts. They begin feeding on the fresh silks and work down.to the developing grain. When full grown (fig. 3), they are about three-eighths of an inch long. One ear may contain a few to several hundred maggots. Five ears brought into the laboratory were found to contain 545, 113, 108, 106, and 199 
larvae, respectively, or an average of 214.2 per ear. Of 200 plants examined daily in the fall of 1935, 191 were observed to silk and 188 , or 98.0 percent, because infested. The average length of the larval stage, based on to samples, was 7.46 days (table 2).

The Pupae.-The pupal stage of the fly is passed in a small, brown puparium about one-eighth of an inch in length (fig. 4). In the early stages it is light brown in color, but a it grows older it changes to a dark brown. Before pupation the maggots leave their feeding places and migrate to drier locations. In the laboratory they readily pupated in moist sand, into which they burrowed to the depth of about one-fourth of an inch. Some puparia were found on the tips of the ears among the dry silks, but as only a few were found it is probable that most of the maggots pupate in the snil. The average length of the pupal stage was 7.38 days, on the basis of ten samples reared to maturity.

TABLE 2-DURATION OF LARVAL AND PUPAL STAGES OF EUXESTA STIMATIAS MAYAG̈̈EZ, P. R., 1935-36

\begin{tabular}{|c|c|c|c|c|}
\hline \multirow{3}{*}{ Sample } & \multicolumn{2}{|c|}{ Larval stage } & \multicolumn{2}{|c|}{ Pupal stage } \\
\hline & Individuals & $\begin{array}{l}\text { Mean } \\
\text { duration }\end{array}$ & Individuals & $\begin{array}{l}\text { Mean } \\
\text { duration }\end{array}$ \\
\hline & Number & Days & Number & Days \\
\hline 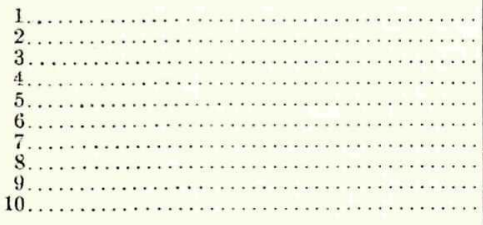 & $\begin{array}{r}19 \\
7 \\
8 \\
12 \\
13 \\
13 \\
17 \\
15 \\
18 \\
8\end{array}$ & $\begin{array}{l}7.42 \\
7.00 \\
7.50 \\
6.58 \\
7.31 \\
7.46 \\
9.06 \\
7.07 \\
7.33 \\
7.88\end{array}$ & $\begin{array}{r}19 \\
7 \\
7 \\
12 \\
11 \\
10 \\
12 \\
13 \\
11 \\
5\end{array}$ & $\begin{array}{l}7.74 \\
7.14 \\
7.64 \\
8.09 \\
7.14 \\
7.74 \\
6.52 \\
7.70 \\
7.12 \\
6.92\end{array}$ \\
\hline Total or average $\ldots \ldots \ldots \ldots \ldots \ldots$ & 130 & 7.46 & 107 & 7.38 \\
\hline
\end{tabular}

Adults.-The adult is a small fly of a dark metallic green color with reddish eyes and wings banded with black (fig. 1). The wings are constantly in motion even when the insect is otherwise at rest. The adults are very abundant in cornfields, where they seem to cluster about the parts of the plant that are likely to be moist, such as the tassel and the silks. They were observed ovipositing on the larvas of young coun, but no larvae seemed to come from these eggs. As many as five females have been observed ovipositing on the same ear at the same time. 


\section{Control}

No attempt was made to control the larvae of this insect in the investigations carried on in Puerio Rico in 1935 and 1936. The protected location of the eggs and the habits of the young maggots in entering the ears after hatching would make control rather difficult. However, some of the experimental control measures used against the corn ear worm (Heliothis obsoleta F.) were found to reduce the number of ears infested with Euxesta maggots. The results are shown in table 3.

Because most of the eggs are laid below the tips of the husks and the maggots feed inside the husks, poisoning with insecticides was difficult. All the inseciicides tested, however, reduced the infestation in some degree, and they ali gave better results in the tests completed in June than in those completed in February. This is, no doubt, due to the fact that the fall applications of dust to the silks were delayed until approximately 50 percent of plants had silk, whereas the spring applications were begun soon after the first silk was observed and continued until silks were dry.

Several hand methods of control also reduced the number of infested ears. Cutting the silks and squeezing the tips of the ears had little effect on the larvae. When the silks were eut the field deposited numerous egg's on the cut tips. Those methods that covered the ear or constricted the husk gave better results than other methods. A paper tip consisted of a piece of brown wrapping paper rolled around the tip of the ear and tied securely with string. These tips were applied soon after the plants silked. The wires, hog rings, and strings were also applied as soon as possible without interfering with pollination. The effect of wires and hog rings was about the same as that of the paper tips, but the strings gave poorer results. 


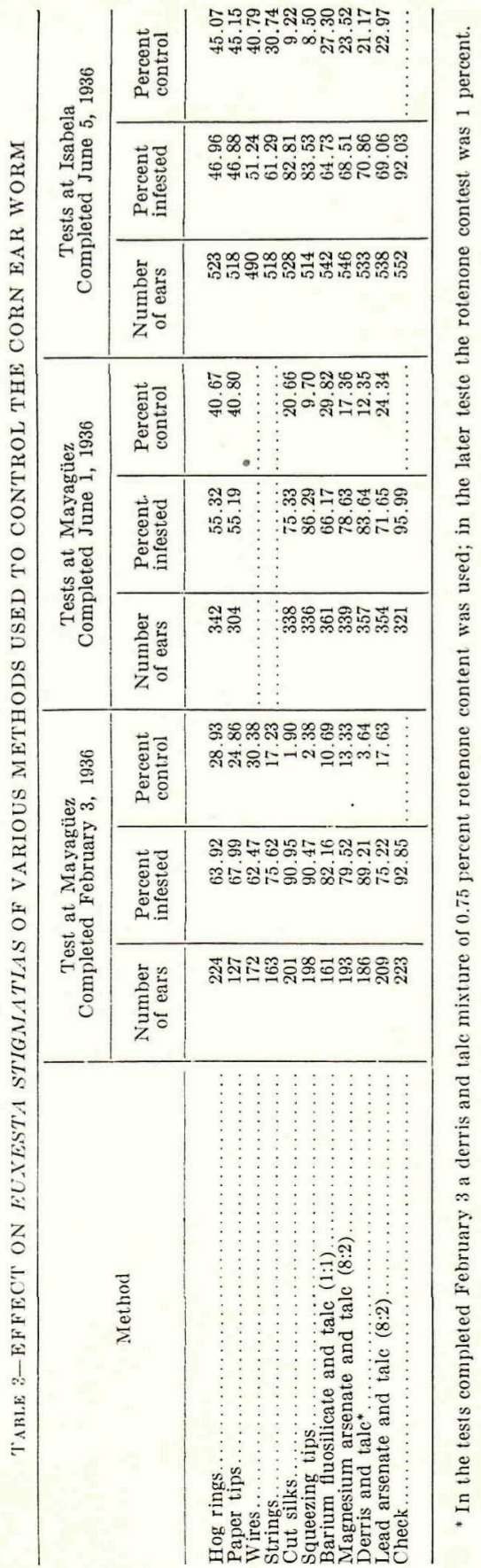




\section{Summary}

The otitid fly Euxesta stigmatias Loew is a serious pest of corn, especially roasting ears for market purposes, in Puerto Rico. The maggots have been observed in all sections of the island and at all seasons of the year. The pest at present seems to be restricted to a tropieal habitat, so far as collection records of this insect are known. In most fields examined a large percentage of the ears were infested, and many entire ears were destroyed. Under laboratory conditions the fly was reared from egg to adult in as few as 18 days; so there are many generations during a year.

Although no special studies were made on control, in some experiments in control of the corn ear worm there was a reduction in the number of ears infested with maggots of Euxesta stigmatias, which suggests that some of these measures may also be useful in controlling this pest. 


\section{Explanation of Plates}

Fig. 1.-Adult of Euxesta stigmatias Loew, the larvae of which cause damage to roasting ears in Puerto Rico.

Fig. 2.-Egg of Euxesta stigmatias.

Fig. 3A.-Larva of Euxesta stigmatias, lateral view. B-Posterior view. C-Posterior spiracle. D-Anterior spiracle.

Fig. 4A.-Puparium of Euxesta stigmatias, lateral view. BPosterior view. C-Posterior spiracle. D-Anterior spiracle. 


\section{PLATE X}

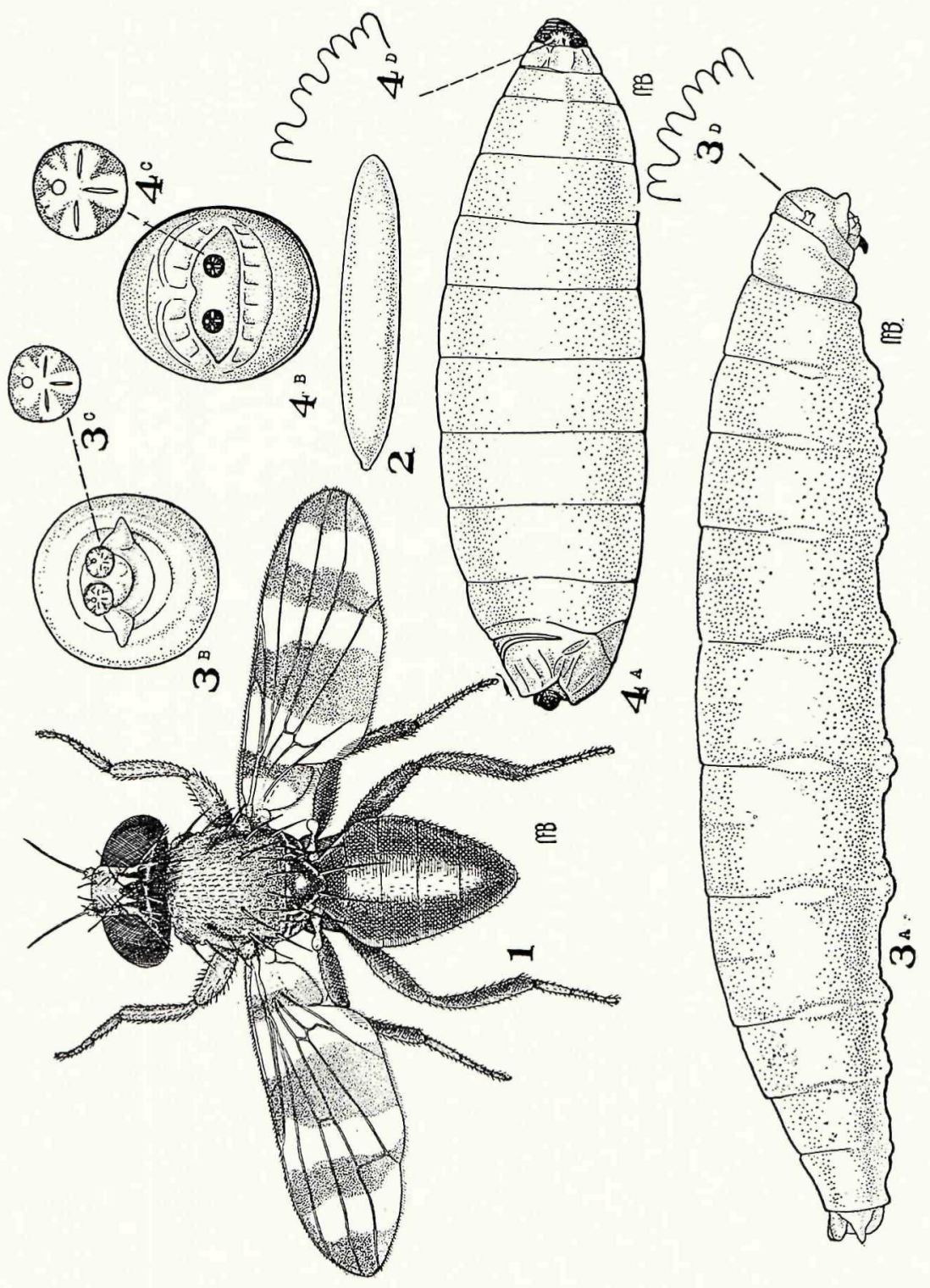

